\title{
Gestão de Serviços em Bibliotecas Públicas: aplicação do 5 W2H na política de aquisição de acervo
}

Service Management in Public Libraries: application of the acquis 5 W2H acquisition policy

\author{
Iracema Fernandes Massaroni \\ Mestranda do Programa de Pós-Graduação em Biblioteconomia da UNIRIO. \\ E-mail: iracemamassaroni@gmail.com
}

Annibal José Roris Rodriguez Scavarda

Doutor em Engenharia de Produção.

E-mail: annibal.scavarda@unirio.br

\section{Resumo}

Apresenta o processo de aquisição de materiais informacionais que compõem o acervo das bibliotecas públicas, a gestão de serviços e a aplicação da ferramenta 5W2H sobre a aquisição do acervo. A utilização desta ferramenta permite a elaboração de um plano de ação proporcionando qualidade na gestão de serviços em bibliotecas públicas, evidenciando ainda o modelo das Bibliotecas Parque, tendo a Biblioteca Parque da Rocinha como laboratório deste estudo. Enfatizar que a biblioteca pública é uma instituição aberta, dinâmica, que através de seus serviços, atividades, funções, contribuem para o desenvolvimento educacional, cultural e social do individuo.

Palavras-chave: Bibliotecas Públicas. Gestão de serviços. Aquisição de acervo. Ferramenta de gestão.

\begin{abstract}
Displays the process of acquiring informational materials that compose the collection of public libraries, service management and the application of $5 \mathrm{~W} 2 \mathrm{H}$ tool on the acquisition of the collection, the use of this tool allows the development ofan action plan providing quality services management in public libraries, still showing the model of the Park libraries, with the Rocinha Park Library as a laboratory study. Emphasize that the public library is an open institution, dynamic, which through its services, activities, functions, contribute to the educational, cultural and social of the individual.
\end{abstract}

Keywords: Public Libraries. Management services. Collection of acquisition. Management tool.

InCID: R. Ci. Inf. e Doc., Ribeirão Preto, v. 6, n. 1, p. 4-16, mar./ago. 2015.

DOI: 10.11606/issn.2178-2075.v6i1p4-16 
Gestão de Serviços em Bibliotecas Púbicas: aplicação do 5W2H na política de aquisição de acervo

\section{Introdução}

As bibliotecas sempre foram muito mais que um depósito, uma estante de livros. Sua função vai além de um repositório do conhecimento, um espaço de convivência e difusão da informação. Segundo Milanesi (1998), a ciência é cumulativa e a biblioteca tem a função de preservar a memória como se ela fosse o cérebro da humanidade, organizando a informação para que todo ser humano possa usufruí-la.

A biblioteca é um local de interação entre a leitura e o leitor, um local de conservação e preservação da memória, de organização e tratamento da informação e acima de tudo de disseminação da cultura. A biblioteca pública é o centro de informações da comunidade, ela deve proporcionar aos seus usuários serviços e atividades que agreguem cada vez mais valores a população que se utiliza destes serviços.

O objetivo deste artigo é fazer uma leitura do processo de aquisição de materiais que compõem o acervo das bibliotecas, evidenciando o modelo das Bibliotecas Parque, tendo o C4/Biblioteca Parque da Rocinha como laboratório deste estudo. Enfatizar que a biblioteca pública é uma instituição aberta, dinâmica, que através de seus serviços, atividades, funções, contribuem para o desenvolvimento educacional, cultural e social do individuo.

Para embasar o presente artigo faz-se necessário definir o que é uma biblioteca pública e o quanto ela é importante para a comunidade a qual está inserida. Quando bem planejada e aparelhada/equipada, ela pode se tornar um espaço agradável de modo a atrair cada vez mais usuários.

$\mathrm{Na}$ seção 2, Metodologia, são apresentadas as abordagens utilizadas neste artigo, acompanhada em seguida da seção 3, Biblioteca Pública, conceituando esta instituição pública de acordo com a literatura na área da Ciência da Informação, já na seção 4 traz um breve histórico da Biblioteca Parque da Rocinha, enquanto que na seção 5, apresentamos a gestão de serviços em bibliotecas, com enfoque na aplicação da ferramenta $5 \mathrm{~W} 2 \mathrm{H}$ na aquisição de acervo. E, por fim, acrescentamos as considerações finais. 
Iracema Fernandes Massaroni e Annibal José Roris Rodriguez Scavarda

\title{
2. Metodologia
}

O estudo foi desenvolvido com base em pesquisa qualitativa. A sustentação teórica foi baseada em resoluções e textos de autores como Waldomiro Vergueiro, Simone Weitzel, Luís Milanesi, Maciel e Mendonça, além de artigos e sites, objetivando apresentar o que diz a literatura.

Neste contexto destaca-se que:

\begin{abstract}
A pesquisa qualitativa envolve o estudo do uso e a coleta de uma variedade de matérias empíricas - estudo de caso; experiência pessoal; introspecção; história de vida; entrevista; artefatos; textos e produção culturais; textos observacionais, históricos, interativos e visuais. [...]. Entende-se, contudo, que cada prática garante uma visibilidade diferente ao mundo. Logo, geralmente existe um compromisso no sentido do emprego de mais de uma prática interpretativa em qualquer estudo (DENZIN; LINCOLN, 2005, p. 17).
\end{abstract}

Para atingirmos o objetivo deste artigo buscamos também, além das fontes bibliográficas, a análise da realidade encontrada dentro das favelas ${ }^{1}$ atendidas pelo projeto Bibliotecas Parque, sendo nosso foco a prestação de serviços de informação para os usuários desta comunidade.

A realidade desta favela, bem como de tantas outras na cidade do Rio de Janeiro que sofrem coma violência oriunda de grupos criminosos ligados ao tráfico de drogas, opressão e baixa qualidade de vida, situação similar com a realidade da cidade de Medellín (Colômbia) que passou por uma transformação a partir de 2004 tornando-se líder nacional e internacional pelo projeto cultural implantado, denominado Parques Biblioteca, que se tornaram grandes ícones arquitetônicos, além de ferramentas disponibilizadas para transformar bairros inteiros, com resultados positivos de impactos sociais, tanto educativos quanto culturais.

Foi empregado a aplicação do 5W2H sobre aquisição de acervo, o $5 \mathrm{~W}$ corresponde às palavras de origem inglesa What, When, Why, Where e Who, e o $2 \mathrm{H}$, à palavra How e à expressão HowMuch. É uma ferramenta que “consiste em uma maneira de estruturarmos o pensamento de uma forma bem organizada e materializada antes de implantarmos alguma solução no negócio", conforme esclarece Behr, Moro, Estabel (2008, p. 39).

\footnotetext{
1 Respeito aqui a grafia da palavra favela, conforme aponta Fernando Ermiro, Historiador e morador da favela da Rocinha, que informa que há 100 anos o nome favela vem sendo utilizado, pelos próprios gerando identidade de grupo e pertencimento, ideologicamente na ausência do termo proletário que se opunha ao termo burguês, o "modelo cultural" favelado serve de via alternativa ao "modelo cultural" burguês.
} 
Gestão de Serviços em Bibliotecas Púbicas: aplicação do 5W2H na política de aquisição de acervo

Também utilizamos o método indutivo, aonde o pesquisador por meio de um levantamento particular, chega a determinadas conclusões gerais, ou seja, parte-se do específico para o geral (MARCONI; LAKATOS, 2003, p. 86). Diante deste parâmetro e conforme Alves $(2005$, p.44) “a pesquisa científica exige método e ordenação. Conhecer alguma coisa é analisá-la profundamente, obedecendo a uma série de etapas e fatores”.

\title{
3. Biblioteca Pública
}

A Biblioteca Pública é um local de desenvolvimento constante da cultura. Ela proporciona a igualdade de acesso às fontes de informações, em seus mais diversos suportes, fortalecendo a prática da cidadania e a formação da identidade cultural de uma sociedade. De acordo com o Manifesto da UNESCO para Bibliotecas Públicas (1994):

\begin{abstract}
A liberdade, a prosperidade e o desenvolvimento da sociedade e dos indivíduos são valores humanos fundamentais. Só serão atingidos quando os cidadãos estiverem na posse da informação que lhes permita exercer os seus direitos democráticos e ter um papel ativo na sociedade. A participação construtiva e o desenvolvimento da democracia dependem tanto de uma educação satisfatória, como de um acesso livre e sem limites ao conhecimento, ao pensamento, à cultura e à informação. (UNESCO, 1994 apud BIBLIOTECA NACIONAL (Brasil), 2000, p. 21).
\end{abstract}

A preparação do espaço físico da biblioteca é de fundamental importância para que seu usuário possa usufruir e interagir com o ambiente da melhor forma possível. Esse espaço deve ter áreas separadas para: armazenamento do acervo (local do acervo), espaço de leitura, pesquisa e referência, atividades culturais, área de circulação e de lazer, serviços internos.

Seu acervo deve estar sempre atualizado e levar em consideração as necessidades informacionais da sua comunidade, de acordo também com os recursos financeiros disponíveis. Além dos livros, colocar à disposição de todos que a frequentam outros materiais informativos como filmes, fotografias, gravuras, folhetos, jornais, internet, acesso a outras fontes de informação através de sistemas informatizados.

Para que seus serviços sejam adequados e acessíveis a todos, é muito importante que a biblioteca conte com profissionais adequados para o seu pleno funcionamento. Além de bibliotecários, esse espaço deve contar com pedagogos, assistentes sociais, animadores culturais, entre outros profissionais que irão assegurar à qualidade dos serviços oferecidos pela biblioteca.

InCID: R. Ci. Inf. e Doc., Ribeirão Preto, v. 6, n. 1, p. 4-16, mar./ago. 2015. 
Iracema Fernandes Massaroni e Annibal José Roris Rodriguez Scavarda

Apesar de ter uma missão tão importante junto a sociedade, a biblioteca pública enfrenta uma série de dificuldades para manter esse espaço vivo e atuante junto à sociedade. A falta de recursos financeiros, a infraestrutura precária, acervo muitas vezes desatualizado, quadro de funcionários reduzido, são alguns dos problemas enfrentados pelos profissionais (as), que administram esse espaço, impossibilitando a prestação de serviços de qualidade por esta instituição.

\begin{abstract}
A biblioteca pública é da responsabilidade das autoridades locais e nacionais. Deve ser objeto de uma legislação específica e financiada pelos governos nacionais e locais. Tem de ser uma componente essencial de qualquer estratégia em longo prazo para a cultura, o acesso à informação, a alfabetização e a educação (UNESCO, 1994 apud BIBLIOTECA NACIONAL (Brasil), 1995, p. 32).
\end{abstract}

Embora com todas as dificuldades enfrentadas não se pode esquecer que a biblioteca pública é a base para a formação futuros de leitores. Um espaço público, aberto a todos, um centro de informação e de cultura da comunidade.

\title{
4. Biblioteca Parque da Rocinha
}

O modelo de Biblioteca Parque surgiu em Medellín, Colômbia. Considerada, até meados dos anos 1990, uma das cidades mais perigosas do mundo, Medellín colocou em prática diversas medidas como: campanha de desarmamento, formação de mediadores de conflitos de bairro e melhor transporte público, no intuito de promover o bem estar social e a segurança pública de sua população.

Em 2003, com o novo projeto de cidade, as bibliotecas foram interligadas em uma rede e passaram a ser concebidas com funções ampliadas, ou seja, como centros culturais e comunitários que não podiam se limitar a prestar os serviços bibliotecários tradicionais, e sim espaços públicos inclusivos e igualitários, propiciando lugares para o encontro, a educação, a recreação, a cultura e a arte. Medellín passou a ser líder nacional e internacional pelo projeto cultural implantado, denominado Parques-biblioteca, que tornaram-se grandes ícones arquitetônicos, além de ferramentas disponibilizadas para transformar bairros inteiros, com resultados positivos de impactos sociais, tanto educativos quanto culturais.

A partir do exemplo da cidade de Medellín, a cidade do Rio de Janeiro, através de seus governantes, em particular da Secretaria Estadual de Cultura, não mediu esforços para implantar com a denominação de Biblioteca Parque esse novo centro de estudos e cultura, que teve como plano piloto a Biblioteca Parque de Manguinhos, situada na comunidade que tem o 
Gestão de Serviços em Bibliotecas Púbicas: aplicação do 5W2H na política de aquisição de acervo

mesmo nome do bairro e que foi inaugurada em 2010, dando oportunidade para a implantação de novas Bibliotecas Parque nas favelas do Rio de Janeiro, cujo objetivo era o de oferecer à população acessibilidade ampla, dispondo de qualidade física, humana e de serviços diversificados, de modo a propiciar melhor cultura e lazer a todos que necessitam.

O C4\%/Biblioteca Parque da Rocinha é a terceira de uma rede de bibliotecas, inaugurada no dia 4 de junho de 2012. Ela surge com o compromisso de oferecer suporte em locais onde a cultura, o acesso à informação são escassos. Realiza ações e projetos culturais e de promoção de leitura nos mais diversos suportes visando incentivar a criação artística em todas as suas formas de expressão. Oferece ainda ambientes arejados, possibilitando ao leitor usufruir de espaços apropriados para atividades culturais e serviços diversos, o que torna a biblioteca um espaço diferenciado, dinâmico e importante para seus usuários.

\section{Aquisição De Acervo Para As Bibliotecas Parque, Com Foco Na Gestão De Serviços E Aplicação Do 5w2h}

Para alcançarmos o objetivo proposto se faz necessário buscarmos entender a gestão de serviços e a aplicação do 5W2H sobre aquisição de acervo.

$\mathrm{O} 5 \mathrm{~W} 2 \mathrm{H}$ é uma ferramenta de gestão que podemos utilizar na aplicação de aquisição de acervos, permitindo a elaboração de um bom plano de ação. As bibliotecas lidam hoje com uma variedade de materiais informacionais e o grande desafio é como desenvolver um acervo que preze pela qualidade de suas coleções, visando à necessidade de prestar serviços que contemplem as necessidades de seus usuários.

Assim, buscar alguns conceitos para compreendermos o significado de "serviços" é fundamental.

A literatura aponta que a gestão de serviços começou a criar força a partir da década de 1980 e 1990, devido a grande atenção que passa a ter nos meios empresariais e acadêmicos.

Favareto (2012) observa que:

\footnotetext{
2 C4 quer dizer Centro de Convivência, Comunicação e Cultura, a inclusão dessa Sigla na frente da Nomenclatura Biblioteca Parque da Rocinha, foi uma conquista do movimento comunitário nas décadas de 1970, 1980 e 1990.
}

InCID: R. Ci. Inf. e Doc., Ribeirão Preto, v. 6, n. 1, p. 4-16, mar./ago. 2015. 
Iracema Fernandes Massaroni e Annibal José Roris Rodriguez Scavarda

\begin{abstract}
Um assunto que vem ganhando destaque e sendo pesquisado na área de gestão de operações é a prestação de serviços. Até a década de 70 do século passado, o estudo da gestão de uma empresa tratava quase exclusivamente das operações de transformação. A partir da década de 80 , as publicações acadêmicas passaram a tratar da "gestão de operações e serviços" e somente na última década do século XX é que se consolidou a "gestão de serviços" (FAVARETO, 2012, p. 3).
\end{abstract}

Kotler $\left(2000^{3}\right.$ apud VITAL; FLORIANI, 2009, p. 25) salientam que "serviço é qualquer ato ou desempenho que uma parte possa oferecer a outra e que seja essencialmente intangível e não resulte na propriedade de nada. Sua produção pode ou não estar vinculada a um produto físico".

De acordo com Passos e Menegatti (2013, p. 154) "compreender o gerenciamento dos processos é um elemento necessário para a prestação do serviço, e visa a maior eficiência com o menor custo". Assim deve-se entender que, a visibilidade das operações pode variar, mas é decisiva para a qualidade do serviço.

Trazendo estes conceitos para área da biblioteconomia, Behr; Moro e Estabel (2008, p. 32) salientam que "alguns autores ao tratarem sobre gestão, na área biblioteconômica, apresentam a visão empresarial em que o bibliotecário exerce a função de administrador, o usuário é o cliente e o serviço oferecido é o produto".

Para consolidar estes conceitos, Spudeit e Führ (2011, p. 42), apontam que as unidades de informação (bibliotecas, centros e sistemas de informação e documentação), apesar de serem organizações sociais sem fins lucrativos, prestam serviços tangíveis e intangíveis para a sociedade que perpassam por operações que requerem também a definição e aplicação de estratégias.

Portanto, o gerenciamento dos serviços em bibliotecas pode ser um aliado no processo de aquisição de materiais para comporem o acervo das bibliotecas está sob o "guarda-chuva" das políticas de desenvolvimento de coleções. No entanto, para entendemos o processo faz-se necessário conceituarmos também dentro da área o sentido de Desenvolvimento de Coleções na formação do acervo. Na preparação da política de acervo é necessário que seja estabelecido os objetivos institucionais, visando a qualidade dos materiais adquiridos que irão compor o acervo. Várias serão as tomadas de decisões que implicarão no envolvimento não só do bibliotecário, mas também de toda a instituição, pois as decisões serão tomadas em conjunto, seguindo normas e diretrizes, que passarão a nortear o desenvolvimento de coleções.

\footnotetext{
${ }^{3}$ KOTLER, P. Administração de marketing. São Paulo: Prentice Hall, 2000.
}

InCID: R. Ci. Inf. e Doc., Ribeirão Preto, v. 6, n. 1, p. 4-16, mar./ago. 2015. 
Gestão de Serviços em Bibliotecas Púbicas: aplicação do 5W2H na política de aquisição de acervo

O desenvolvimento de coleções dará parâmetros para evitar que o acervo cresça desordenadamente sem metas ou objetivos definidos, que segundo Miranda (2004, p. 5), “implica em sistematizar e criar procedimentos para seleção, aquisição, avaliação e desbastamento do acervo".

A Política de Seleção de acordo com Vergueiro (1995, p. 68) deve informar sobre os seguintes itens: identificação dos responsáveis pela seleção de materiais; os critérios utilizados; os instrumentos auxiliares; as políticas específicas; os documentos correlatos. São os critérios que garantem a qualidade e o ajustamento necessário, para atender as reais necessidades dos usuários.

$\mathrm{Na}$ preparação da política faz-se necessário que sejam estabelecidos os objetivos institucionais para dar maior direcionamento do acervo. Várias serão as tomadas de decisões que implicarão no envolvimento não só do bibliotecário, mas também de toda a instituição, pois as decisões serão tomadas em conjunto, seguindo normas e diretrizes, que passarão a nortear o desenvolvimento do acervo.

Desse modo, a seleção atuará juntamente com a necessidade de se ampliar e melhorar o acervo, possibilitando a incorporação de materiais que condigam com os interesses de seus usuários. Esse processo é como um exercício baseado em conhecimento detalhado da biblioteca, que caracteriza um perfil altamente individualizado e que poderá variar de instituição para instituição. O processo de seleção e de aquisição permite a formação de um acervo mais consistente, que atenda às expectativas da comunidade a que vai servir.

Para garantir a qualidade na aquisição de novos materiais é necessário que sejam estabelecidos critérios para seleção. Estabelecer critérios de seleção segundo Vergueiro (1989, p. 26), trata de:

[...] uma tarefa bastante individual, subjetiva e que deve ser realizada pelos profissionais levando em consideração a comunidade a que estão servindo, considerar os recursos financeiros disponíveis para aquisição e as próprias características do assunto ou material objeto da atividade de seleção, faz-se necessário a criação de uma comissão consultiva composta tanto por usuários como por profissionais da instituição mantenedora e bibliotecários.

Vergueiro (1995, p. 68) procura categorizar alguns critérios tais como: adequação do material aos objetivos da instituição; autoridade do autor e/ou editor; atualidade; qualidade técnica; escassez de material sobre o assunto na coleção; aparecimento do título em bibliografias e índices; cobertura/tratamento; custo justificado; idioma acessível; 
Iracema Fernandes Massaroni e Annibal José Roris Rodriguez Scavarda

relevância/interesse; estilo; número de usuários potenciais que poderão utilizar o material; precisão; condições físicas do material, permitindo um desenvolvimento equilibrado ao que se refere às estruturas das coleções.

Corroborando com a literatura da área o processo de Aquisição de materiais para a composição dos acervos implica numa tomada de decisão que irá impactar na qualidade das coleções.

Para Weitzel (2012) e de acordo com Evans (2000, p. 293) o processo de aquisição "envolve a localização e a aquisição de itens identificados como apropriados para a Coleção". Para Figueiredo (1998) e Maciel e Mendonça (2000), salientam que aquisição é um processo que implementa as decisões da seleção por meio da compra, doação e permuta de documentos, incluindo a alocação de recursos e registro dos itens para fins de patrimônio.

Segundo Figueiredo (1993, p. 40) "as necessidades da biblioteca existem e devem ser respondidas, tanto quanto as necessidades dos seus leitores. Não há uma regra fixa como base média equilibrada de assuntos". É importante o bibliotecário conhecer as necessidades de seus leitores para estabelecer a estrutura da coleção de sua biblioteca de modo a buscar equilíbrio de assuntos.

O processo de aquisição de materiais para serem inseridos nos acervos precisa ser tratado com extrema acuidade pelos responsáveis na hora da seleção, tanto que Weitzel (2012, p. 186) observa que "a necessidade de uma política de aquisição já era defendida por Peignot (1823, p. 5) como o primeiro passo para acertar nas aquisições em uma biblioteca”.

Ainda de acordo com a autora, a forma mais certa para evitar dissabores aos quais estamos acostumados a enfrentar é não fazer nenhuma aquisição sem estabelecer um planejamento, após este plano ter sido traçado, segui-lo criteriosamente, e não abandoná-lo. Seguindo esta linha de raciocínio visando alcançar sucesso, no processo de aquisição de materiais para compor o acervo das Bibliotecas Parque da cidade do Rio de Janeiro, elaborouse um modelo baseado na ferramenta de gestão $5 \mathrm{~W} 2 \mathrm{H}$, cujo planejamento é atingir o resultado desejado.

Segundo Behr; Moro e Estabel (2008, p. 39) o 5W2H é uma ferramenta de gestão que podemos utilizar na aplicação de aquisição de acervos, permitindo a elaboração de um bom plano de ação e esta ferramenta permite a estruturação do pensamento de uma forma bem organizada e materializada antes de implantarmos alguma solução na ação.

InCID: R. Ci. Inf. e Doc., Ribeirão Preto, v. 6, n. 1, p. 4-16, mar./ago. 2015. 
Gestão de Serviços em Bibliotecas Púbicas: aplicação do 5W2H na política de aquisição de acervo

A literatura esclarece que o 5W2H é uma sigla que se popularizou na linguagem empresarial que vem a ser um "micro-checklist", que utilizado pode auxiliar a nos lembrarmos dos seis pontos principais de um plano de ação.

Assim, quando nos deparamos com determinada tarefa, nos perguntamos sobre cada uma dessas palavras e escrevemos as respostas. Essa ferramenta segundo a autora ajuda a melhorar a segregação de tarefas dentro de um processo, permitindo gerenciar e visualizar como os processos estão se desenvolvendo.

O 5W2H origina-se das seis palavras em inglês: What; When; Who; Why; Where; How, que traduzindo para o português significam: O Que; Quando; Quem; Onde; Como.

Tabela 1 - Ferramenta 5W2H

\begin{tabular}{|c|c|c|c|c|c|c|c|}
\hline Atividade & O Quê? & Quando? & Por quê & Onde? & Como? & Quem? & Quanto? \\
\hline $\begin{array}{l}\text { Definição da } \\
\text { política de } \\
\text { Aquisição } \\
\text { por compra }\end{array}$ & $\begin{array}{l}\text { Definir } \\
\text { regras para } \\
\text { aquisição } \\
\text { dos } \\
\text { materiais } \\
\text { para o } \\
\text { acervo }\end{array}$ & $\begin{array}{l}\text { Uma } \\
\text { vez por } \\
\text { ano }\end{array}$ & $\begin{array}{l}\text { Para } \\
\text { manter o } \\
\text { acervo } \\
\text { atualizado }\end{array}$ & $\begin{array}{l}\mathrm{Na} \\
\text { Bibliotec } \\
\text { a Parque } \\
\text { da } \\
\text { Rocinha }\end{array}$ & $\begin{array}{l}\text { Através } \\
\text { de } \\
\text { reuniões } \\
\text { internas }\end{array}$ & $\begin{array}{l}\text { Diretores } \\
\mathrm{e} \\
\text { coordenad } \\
\text { ores da } \\
\text { biblioteca }\end{array}$ & 12.0000 \\
\hline $\begin{array}{l}\text { Organização } \\
\text { da lista de } \\
\text { pedidos } \\
\text { (proveniente } \\
\text { s da seleção) }\end{array}$ & $\begin{array}{l}\text { Acrescent } \\
\text { ar os itens } \\
\text { sugeridos } \\
\text { pelos } \\
\text { usuários }\end{array}$ & $\begin{array}{l}\text { Uma } \\
\text { vez por } \\
\text { semana }\end{array}$ & $\begin{array}{l}\text { Para } \\
\text { atender à } \\
\text { demanda } \\
\text { do } \\
\text { usuário }\end{array}$ & $\begin{array}{l}\text { No } \\
\text { balcão de } \\
\text { atendime } \\
\text { nto da } \\
\text { biblioteca }\end{array}$ & $\begin{array}{l}\text { Atualizan } \\
\text { do a lista } \\
\text { procedent } \\
\text { e da } \\
\text { seleção }\end{array}$ & $\begin{array}{l}\text { Bibliotecári } \\
\text { os de } \\
\text { referências }\end{array}$ & 00,00 . \\
\hline $\begin{array}{l}\text { Complement } \\
\text { ação dos } \\
\text { dados } \\
\text { apropriados } \\
\text { (Organizaçã } \\
\text { o dos dados } \\
\text { bibliográfico } \\
\text { s) }\end{array}$ & $\begin{array}{l}\text { Padronizar } \\
\text { a lista por: } \\
\text { Título, } \\
\text { Editora, } \\
\text { Autor, } \\
\text { Assunto, } \\
\text { Série, } \\
\text { ISBN }\end{array}$ & $\begin{array}{l}\text { Uma } \\
\text { vez por } \\
\text { semana }\end{array}$ & $\begin{array}{l}\text { Para } \\
\text { padroniza } \\
\text { r e } \\
\text { facilitar o } \\
\text { processo } \\
\text { de } \\
\text { compra }\end{array}$ & $\begin{array}{l}\text { Sala de } \\
\text { reunião }\end{array}$ & $\begin{array}{l}\text { Conferir } \\
\text { os dados } \\
\text { nos } \\
\text { catálogos } \\
\text { dos } \\
\text { fornecedo } \\
\text { res }\end{array}$ & $\begin{array}{l}\text { Bibliotecá } \\
\text { rio de } \\
\text { referência }\end{array}$ & 00,00 \\
\hline $\begin{array}{l}\text { Verificação } \\
\text { da existência } \\
\text { dos itens nas } \\
\text { coleções }\end{array}$ & $\begin{array}{l}\text { Livros, } \\
\text { periódicos, } \\
\text { DVDs. } \\
\text { Dentre } \\
\text { outros } \\
\text { materiais }\end{array}$ & $\begin{array}{l}\text { Após } \\
\text { atualiza } \\
\text { ção da } \\
\text { lista de } \\
\text { sugestõe } \\
\text { s }\end{array}$ & $\begin{array}{l}\text { Para } \\
\text { evitar } \\
\text { duplicida } \\
\text { de no } \\
\text { acervo }\end{array}$ & $\begin{array}{l}\text { Na base } \\
\text { de dados } \\
\text { e nas } \\
\text { estantes }\end{array}$ & $\begin{array}{l}\text { Comparan } \\
\text { do a } \\
\text { quantidad } \\
\text { e da base } \\
\text { de dados } \\
\text { com as } \\
\text { estantes }\end{array}$ & $\begin{array}{l}\text { Bibliotecá } \\
\text { rio de } \\
\text { referência }\end{array}$ & 00,00 \\
\hline
\end{tabular}


Iracema Fernandes Massaroni e Annibal José Roris Rodriguez Scavarda

\begin{tabular}{|c|c|c|c|c|c|c|c|}
\hline $\begin{array}{l}\text { Seleção dos } \\
\text { fornecedores }\end{array}$ & $\begin{array}{l}\text { Escolher } \\
\text { Editoras, } \\
\text { distribuido } \\
\text { ras ou } \\
\text { livrarias. }\end{array}$ & $\begin{array}{l}\text { Após a } \\
\text { verifica } \\
\text { ção da } \\
\text { existênc } \\
\text { ia dos } \\
\text { itens nas } \\
\text { coleções }\end{array}$ & $\begin{array}{l}\text { Para } \\
\text { avaliar o } \\
\text { melhor } \\
\text { custo e } \\
\text { prazos de } \\
\text { entrega }\end{array}$ & $\begin{array}{l}\text { Setor de } \\
\text { compras }\end{array}$ & $\begin{array}{l}\text { Realizand } \\
\text { o contato } \\
\text { presenciai } \\
\text { s e por e- } \\
\text { mail }\end{array}$ & $\begin{array}{l}\text { Bibliotecá } \\
\text { rio de } \\
\text { Aquisição }\end{array}$ & 00,00 \\
\hline Compra & $\begin{array}{l}\text { Livros, } \\
\text { periódico, } \\
\text { DVDs, } \\
\text { dentre } \\
\text { outros } \\
\text { materiais }\end{array}$ & $\begin{array}{l}\text { Uma } \\
\text { vez por } \\
\text { mês }\end{array}$ & $\begin{array}{l}\text { Para } \\
\text { manter o } \\
\text { acervo } \\
\text { atualizado }\end{array}$ & $\begin{array}{l}\text { Setor de } \\
\text { compras }\end{array}$ & $\begin{array}{l}\text { Requisiçã } \\
\text { o de } \\
\text { pedidos }\end{array}$ & $\begin{array}{l}\text { Bibliotecá } \\
\text { rio de } \\
\text { Aquisição }\end{array}$ & 1.0000 \\
\hline
\end{tabular}

Fonte: Adaptado pela autora (2014)

Por compra:

A Política de Aquisição das Bibliotecas Parque visa garantir por via de orçamento anual a compra de livros, filmes, periódicos, música digital e livros digitais.

As coordenações de acervo farão levantamentos e seleções semanais dos títulos. Todos os itens listados deverão ser aprovados pelas direções de cada unidade e entregues a Gerência de Acervo e seguirá os critérios abaixo:

Metodologia:

1 - Análise e seleção dos títulos

2 - Organização das listas de títulos para aquisição

3 - Entrega da lista de títulos

4 - Divulgação da tarefa de aquisição

InCID: R. Ci. Inf. e Doc., Ribeirão Preto, v. 6, n. 1, p. 4-16, mar./ago. 2015. 
Gestão de Serviços em Bibliotecas Púbicas: aplicação do 5W2H na política de aquisição de acervo

\section{Considerações finais}

Acompanhando a evolução e com o advento da imprensa, as bibliotecas deixaram de ser privilégio de reis, sacerdotes e uns poucos alfabetizados e, nesse sentido com a Revolução Francesa os livros começam a fazer parte do imaginário popular, pois começam a ser colocados à disposição da população. Seguindo a história, com a revolução industrial a biblioteca deixa de ter como objetivo principal a preservação do livro e passa a prestar serviço ao público. Assumindo, portanto a função educativa e passa a atuar incentivando o hábito de leitura.

Portanto as bibliotecas atualmente são espaços dinâmicos cujo objetivo é desenvolver serviços com qualidade, ter em suas coleções publicações que atendam aos seus usuários, nesse sentido pensar em ferramentas de gestão que venham a facilitar e auxiliar a desenvolver um plano de ação, é o objetivo de qualquer biblioteca.

\section{Referências}

ALVES, G. L. O trabalho didático na escola moderna: formas históricas. Campinas: Autores Associados, 2005.

BEHR, A.; MORO, E. L. S.; ESTABEL, L. B. Gestão da biblioteca escolar: metodologias, enfoques e aplicação de ferramentas de gestão e serviços de biblioteca. Ciência da Informação, Brasília, v. 37, n. 2, p. 32-42, maio/ago. 2008. Disponível em: $<\underline{\text { http://revista.ibict.br/ciinf/index.php/ciinf/article/view/1043/756> }}$. Acesso em: 13 nov. 2014.

BIBLIOTECA NACIONAL (Brasil). Biblioteca pública: princípios e diretrizes. Rio de Janeiro: Biblioteca Nacional, 2000. Disponível em:

$<$ http://consorcio.bn.br/consorcio/manuais/manualsnbp/ArquivoFinal28_08.pdf $>$. Acesso em: 08 dez. 2014.

DENZIN, N. K; LINCOLN, Y. S. (Org.). O Planejamento da pesquisa qualitativa: teorias e abordagens; tradução Sandra Regina Netz. Porto Alegre: Artmed, 2005.

EVANS, G. E. Developing library and information center collection. 4. ed. Englewood: Libraries Unlimited, 2000.

FAVARETO, F. Gerenciamento de informações em cadeias de prestação de serviços.

Perspectivas em Gestão \& Conhecimento, João Pessoa, v. 2, n. 1, p. 3-20, jan./jun. 2012.

Disponível em: <http://periodicos.ufpb.br/oj2index.php/pgc>. Acesso em: 10 nov. 2014. 
Iracema Fernandes Massaroni e Annibal José Roris Rodriguez Scavarda

FIGUEIREDO, N. M. Desenvolvimento e avaliação de coleções. Rio de Janeiro: Rabiskus, 1993. Disponível em: <http://pt.scribd.com/doc/78335882/Desenvolvimento-e-Avaliacao-deColecoes\#scribd>. Acesso em: 10 nov.2014.

Desenvolvimento e avaliação de coleções. 2. ed. Brasília: Thesaurus, 1998. MACIEL, A. C.; MENDONÇA, M. A. R. Bibliotecas como organizações. Rio de Janeiro: Interciência, 2000.

MARCONI, M. A.; LAKATOS. Fundamentos de metodologia científica 1. 5. ed. São Paulo: Atlas, 2003.

MILANESI, L. O que é biblioteca, São Paulo: Brasiliense, 1998.

MIRANDA, A. Seleção de material bibliográfico em bibliotecas universitárias brasileiras. In: Estruturas de informação e análise conjuntural: ensaios. Brasília: Thesaurus, 2004. p. 63-85.

PASSOS, K.; MENEGATTI, Y. Avaliação da qualidade dos serviços em unidades de informação: proposição de uma metodologia. Informação e Informação, Londrina, v. 18, n. 3, p. 154 - 174, set./dez. 2013. Disponível em: <http:www.uel.br/revistas/informacao/ 154> Acesso em:10 nov. 2014.

PEIGNOT, G. Manuel du bibliophile. Dijon: V. Lagier Libraire, 1823.

SPUDEIT, D. F. A. O.; FÜHR, F. Planejamento em unidades de informação: qualidade em operações de serviços na Biblioteca do SENAC Florianópolis. Bibliotecas Universitárias, Belo Horizonte, v. 1, n. 1, p. 41-49, jan./jun. 2011.

VERGUEIRO, W. C. S. Desenvolvimento de coleções. São Paulo: Polis: 1989, 96 p.

. Seleção de materiais de informação: princípios e técnicas. Brasília: Briquet de

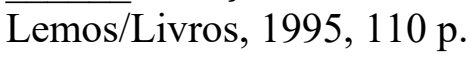

VITAL, L. P.; FORIANI, V. M. Metodologia para planejamento estratégico e gestão de serviços em unidades de informação. Revista Digital de Biblioteconomia e Ciência da Informação, Campinas, v. 6, n. 2, p. 24-44, jan./jun. 2009. Disponível em:

$<$ http://www.sbu.unicamp.br/seer/ojs/index.php/rbci/article/view/403/270>. Acesso em: 10 nov. 2014.

WEITZEL, S. R. Desenvolvimento de coleções: origem dos fundamentos contemporâneos. TrasInformação, Campinas, v. 24, n. 3, p. 179-190, set./dez. 2012. Disponível em: $<$ http://periodicos.puc.campinas.edu.br/seer/index.php/transinfo/article/view/1201/1176>. Acesso em: 13 nov. 2014. 